\title{
Metabolic Mapping of the Effects of Win 55212-2 Intravenous Administration in the Rat
}

Francesco E. Pontieri, M.D., Giuseppe Conti, Ph.D., Alessandro Zocchi, Ph.D., Cesare Fieschi, M.D., and Francesco Orzi, M.D.

The $\left[{ }^{14} \mathrm{C}\right] 2$-deoxyglucose method was applied to measure the effects of the synthetic cannabinoid agonist WIN 55212-2 intravenous administration on glucose utilization in the rat brain. Two doses of the drug, that have been reported previously to increase extracellular dopamine concentrations in the shell of the nucleus accumbens, were used (0.15-0.30 mg/kg). At the lower dose, WIN 55212-2 increased energy metabolism selectively in the accumbens shell. Conversely, the higher dose of the drug reduced glucose utilization in the hippocampal formation and ventromedial thalamic nucleus without affecting energy metabolism in the accumbens shell. These results may be useful to further understanding the addictive potentials of cannabinoid drugs. [Neuropsychopharmacology 21:773-776, 1999] (C) 1999 American College of Neuropsychopharmacology. Published by Elsevier Science Inc.
KEY WORDS: WIN 55212-2; Cannabinoids; Nucleus accumbens; Shell; Hippocampus; Deoxyglucose; Drug abuse

Although Cannabis is the most widely abused substance, the addictive potentials of cannabinoid drugs have not been, to date, completely elucidated. Indeed, experimental studies on cannabinoid abuse have been partially limited by difficulties in maintaining stable rates of self-administration of these drugs by laboratory animals. Several factors, including the slow onset of cannabinoid action (Mansbach et al. 1996), aversive qualities (Mallet and Beninger 1998), and negative effects of cannabinoids on learning and memory (Licht-

From the Department of Neuroscience (FEP, CF, FO), University La Sapienza, Rome, Italy; and I.N.M. Neuromed (GC, AZ, FO), Pozzilli (IS), Italy.

Address correspondence to: Dr. Francesco E. Pontieri, Department of Neuroscience, University La Sapienza, Viale dell'Università, 30, 00185 Roma, Italy.

Received January 14, 1999; revised April 29, 1999; accepted May 20, 1999 . man and Martin 1996; Brodkin and Moerschbaecher 1997) may contribute for the failure of these drugs to be readily self-administered by laboratory animals.

There is, however, evidence that cannabinoids exert neurochemical actions on the central reward pathways similar to those produced by addictive drugs (for review see Gardner and Vorel 1998). In particular, intravenous administration of $\Delta^{9}$-tetrahydrocannabinol (THC) or the synthetic cannabinoid agonist WIN 55212-2 increase extracellular dopamine levels in the shell of the rat nucleus accumbens (Tanda et al. 1997), an effect that resembles those produced by psychomotor stimulants, opiates, and nicotine (Pontieri et al. 1995, 1996). This effect is antagonized by blockade of cannabinoid receptors or $\mu 1$ opioid receptors in the ventral tegmental area (Tanda et al. 1997) and is associated with increased firing of ventral tegmental dopamine neurons (Gessa et al. 1998). Moreover, pharmacologically-induced withdrawal from cannabinoid drugs produces neurochemical changes within the limbic system that are similar to those seen with drugs abuse (Rodriguez de Fonseca et al. 1997; Diana et al. 1997). 
The $\left[{ }^{14} \mathrm{C}\right] 2$-deoxyglucose method (Sokoloff et al. 1977) for measuring local rates of cerebral glucose utilization is a powerful means with which to identify the effects of pharmacological treatments on brain functional activity. Previous reports indicate that acute intravenous administration of several drugs of abuse, such as psychomotor stimulants, morphine, and nicotine, consistently increases glucose utilization in the shell of the rat nucleus accumbens (Pontieri et al. 1994, 1996; Orzi et al. 1996). In the present study, the $\left[{ }^{14} \mathrm{C}\right] 2-$ deoxyglucose method was applied to map brain areas of altered functional activity associated with the acute administration of the synthetic cannabinoid agonist WIN 55212-2 in the rat. The drug was injected intravenously because of previous evidence indicating the relevance of route of administration (Porrino 1993; Pontieri et al. 1998). Two doses of the drug were used ( 0.15 and $0.30 \mathrm{mg} / \mathrm{kg}$ ). These doses were chosen because they were reported previously to produce dose-dependent increases of extracellular dopamine concentrations in the accumbens shell (Tanda et al. 1997).

\section{MATERIALS AND METHODS}

Male Sprague Dawley rats weighing 270-300 g (Charles River, Italy) were housed in group cages under standard temperature conditions on a 12-hour light/dark cycle (light on 08:00-20:00). They had free access to food and water. All procedures were carried out according to the NIH Guide for the care and use of laboratory animals. Experiments were approved by the local Ethical Committee.

On the morning of the experiment, each animal was anesthetized with halothane ( $2 \%$ in oxygen) and polyethylene catheters were inserted into one femoral artery and vein, then tunneled subcutaneously to exit at the nape of the neck (Crane and Porrino 1989). WIN 552122 (Sigma, Italy) was suspended in $0.3 \%$ Tween 80 in saline, as described previously (Tanda et al. 1997). Animals were allowed at least $4 \mathrm{hrs}$ to recover from anesthesia before being injected intravenously with either WIN $55212-2(0.15-0.30 \mathrm{mg} / \mathrm{kg})$ or vehicle (injection volume $1 \mathrm{ml} / \mathrm{kg}$ ).

The $\left[{ }^{14} \mathrm{C}\right] 2$-deoxyglucose procedure was begun $5 \mathrm{~min}$ after the administration of drug or vehicle and carried out with the adaptation for use in freely moving rats (Crane and Porrino 1989). Briefly, a pulse of $\left[{ }^{14} \mathrm{C}\right] 2-$ deoxyglucose $(100 \mu \mathrm{Ci} / \mathrm{kg}$, specific activity $50-55 \mathrm{mCi} /$ $\mathrm{mmol}$, Amersham, UK) was injected intravenously and timed arterial blood samples were collected. Blood samples were immediately centrifuged and tested for plasma glucose concentrations by means of the Beckman II Glucose Analyzer (Beckman, Italy) and ${ }^{14} \mathrm{C}$ concentrations by liquid scintillation counting (Beckman, Italy). Approximately $45 \mathrm{~min}$ after the administration of the tracer, rats were killed by the intravenous injection of pentobarbital. The brains were rapidly removed, frozen in isopentane at $-40^{\circ} \mathrm{C}$, and stored at $-70^{\circ} \mathrm{C}$ until sectioning. Coronal brain sections were cut in a cryostat maintained at $-22^{\circ} \mathrm{C}$, taw-mounted on glass coverlips, dried on a hot plate, and autoradiographed on Kodak Min-R x-ray films (Kodak, Italy) along with a set of ${ }^{14} \mathrm{C}$ standards (Amersham, UK). Autoradiograms were analyzed by quantitative densitometry with a computerized image processing system (Scion Image for Windows 95).

Optical density measurements for each structure were made in at least five consecutive sections. Local tissue ${ }^{14} \mathrm{C}$ concentrations were determined from the optical densities and a calibration curve obtained from densitometric analysis of the calibrated standards. Rates of glucose utilization were then calculated from local ${ }^{14} \mathrm{C}$ concentrations and the time courses of arterial plasma glucose and $\left[{ }^{14} \mathrm{C}\right] 2$-deoxyglucose concentrations by means of the operational equation of the method (Sokoloff et al. 1977). Rates of glucose utilization were determined in 26 cerebral structures. Two-way analysis of variance for repeated measures (brain structures) was applied to the results. Huynh-Feldt correction was used for the repeated measures. The factors were represented by the two doses of the drug and the brain areas examined. We performed post-hoc test since the initial aim of this study was to identify cerebral areas that most contributed to the significant treatment effect or to the significant treatment $\times$ structure interaction. Thus, independently for each brian area, mean values of glucose utilization were compared by Dunnett's $t$-test for assessing the statistical significance of the difference between the control and the treated groups.

\section{RESULTS}

The intravenous administration of WIN 55212-2 at the doses used did not produce any significant behavioral change. The effects of the WIN 55212-2 on local cerebral glucose utilization in the rat are summarized in Table 1. Two-way analysis of variance for repeated measures showed a significant structure $\times$ treatment interaction $(p<.001 ; p<.05$ after Huynh-Feldt correction) suggesting an effect of the drug limited to selected brain areas. The structures which mostly contributed to the interaction were the shell of the nucleus accumbens, the hippocampus, and the ventromedial thalamic nucleus (Table 1). There was no significant treatment effect. As expected, there was a significant structure effect, which simply indicates the heterogeneous metabolism of the brain.

\section{DISCUSSION}

The results of the present study demonstrate that intravenous administration of WIN 55212-2 produces dose- 
Table 1. Effects of the Administration of WIN 55212-2 on Local Cerebral Glucose Utilization in the Rat ( $\mu \mathrm{mol} / 100 \mathrm{~g} / \mathrm{min})$

\begin{tabular}{lccc}
\hline & \multicolumn{3}{c}{ WIN $\mathbf{5 5 2 1 2 - 2}$ (mg/kg) } \\
\cline { 2 - 4 } Structure & $\mathbf{0 . 0 0}$ & $\mathbf{0 . 1 5}$ & $\mathbf{0 . 3 0}$ \\
\hline Prefrontal cortex, medial & $69 \pm 6$ & $64 \pm 4$ & $68 \pm 5$ \\
Prefrontal cortex, lateral & $75 \pm 7$ & $73 \pm 2$ & $73 \pm 5$ \\
Nucleus accumbens, shell & $71 \pm 4$ & $87 \pm 4^{*}$ & $67 \pm 5$ \\
Nucleus accumbens, core & $76 \pm 6$ & $80 \pm 2$ & $74 \pm 7$ \\
Caudate putamen, ventral & $87 \pm 7$ & $74 \pm 3$ & $73 \pm 6$ \\
Anterior cingulate cortex & $94 \pm 7$ & $85 \pm 2$ & $89 \pm 8$ \\
Lateral septal nucleus & $57 \pm 6$ & $54 \pm 2$ & $55 \pm 4$ \\
Medial septal nucleus & $73 \pm 8$ & $71 \pm 1$ & $72 \pm 5$ \\
Amygdala, basolateral & $76 \pm 8$ & $70 \pm 3$ & $64 \pm 4$ \\
Amygdala, central & $48 \pm 4$ & $53 \pm 1$ & $43 \pm 3$ \\
Thalamus, ventromedial & $121 \pm 10$ & $98 \pm 6$ & $94 \pm 4^{*}$ \\
Thalamus, ventrolateral & $95 \pm 9$ & $81 \pm 4$ & $76 \pm 3$ \\
Thalamus, dorsomedial & $111 \pm 12$ & $99 \pm 9$ & $88 \pm 6$ \\
Entopeduncular nucleus & $53 \pm 5$ & $53 \pm 1$ & $47 \pm 4$ \\
Subthalamic nucleus & $83 \pm 8$ & $80 \pm 5$ & $74 \pm 2$ \\
Hippocampus, CA1 & $67 \pm 4$ & $61 \pm 2$ & $54 \pm 3^{*}$ \\
Hippocampus, CA2 & $75 \pm 6$ & $63 \pm 2$ & $53 \pm 3^{*}$ \\
Hippocampus, CA3 & $78 \pm 6$ & $64 \pm 3$ & $52 \pm 2^{*}$ \\
Hippocampus, CA4 & $66 \pm 4$ & $62 \pm 3$ & $51 \pm 3^{*}$ \\
Dentate gyrus & $74 \pm 5$ & $65 \pm 3$ & $56 \pm 4^{*}$ \\
Habenula, medial & $76 \pm 8$ & $75 \pm 5$ & $61 \pm 4$ \\
Habenula, lateral & $110 \pm 13$ & $94 \pm 7$ & $85 \pm 3$ \\
Substantia nigra compacta & $74 \pm 6$ & $70 \pm 3$ & $62 \pm 3$ \\
Substantia nigra reticulata & $66 \pm 5$ & $63 \pm 3$ & $57 \pm 3$ \\
Superior colliculus, external & $83 \pm 9$ & $98 \pm 6$ & $74 \pm 4$ \\
Superior colliculus, deep & $90 \pm 10$ & $106 \pm 8$ & $78 \pm 4$ \\
\hline
\end{tabular}

Data represent means \pm S.E.M., $n=4$ for each group. ${ }^{*} p<.05$ different from .00, Dunnett's $t$-test statistic.

related effects on cerebral glucose utilization in the rat. As shown in Table 1, the lower dose of WIN 55212-2 used $(0.15 \mathrm{mg} / \mathrm{kg})$ increased glucose metabolism in the shell of the nucleus accumbens. This effect is similar to the ones measured previously following the intravenous injection of psychomotor stimulants (Pontieri et al. 1994), morphine (Orzi et al. 1996), or nicotine (Pontieri et al. 1996). It is relevant to note that the same dose of WIN 55212-2 has been shown to increase extracellular dopamine levels in the accumbens shell in the rat (Tanda et al. 1997). Taken together, the findings strongly suggest a preferential effect of this dose of the drug at the level of the mesolimbic reward pathway's projection field, thus providing further evidence for a similarity between the effects of cannabinoids and those of drugs with powerful, well documented addictive properties.

The higher dose of WIN 55212-2 used $(0.30 \mathrm{mg} / \mathrm{kg})$, however, produced metabolic decreases of the hippocampal formation but no change in the accumbens shell. The decrease of glucose utilization in the hippocampus and dentate gyrus might represent the functional correlate of the negative action of the drug on learning and memory circuities (Lichtman and Martin 1996; Brodkin and Moerschbaecher 1997). In this re- spect, there is evidence for the inhibition of hippocampal acethylcholine release by cannabinoids (Gessa et al. 1997). Moreover, metabolic depression was measured in the ventromedial thalamic nucleus that has been implicated in arousal mechanisms (Sakai et al. 1998).

It is notable that the higher dose of WIN 55212-2 used $(0.30 \mathrm{mg} / \mathrm{kg})$ did not modify glucose utilization in the shell of the nucleus accumbens, where the very same dose increases extracellular dopamine concentrations (Tanda et al. 1997). There is no specific reason why increased dopamine release should be coupled with increased glucose metabolism, but in several occasions substances of abuse had consistently produced both effects in the shell of the accumbens (Pontieri et al. 1998), when injected intravenously at single unit doses corresponding to those that sustain self-administration. It is, therefore, a possibility that the lack of effects of 0.30 $\mathrm{mg} / \mathrm{kg}$ of WIN 55212-2 on energy metabolism in the shell of the nucleus accumbens is dependent upon complex neurochemical interactions occurring as the consequence of the effects of the drug on other neuronal pathways, including the hippocampal formation.

A previous $\left[{ }^{14} \mathrm{C}\right] 2$-deoxyglucose study (Margulies and Hammer 1991) reported the effects of THC administration on glucose utilization in the rat using doses and route of administration different from the ones utilized herein. In that study, a biphasic effect on limbic structures was observed. However, no changes in glucose utilization were measured in the nucleus accumbens. In our opinion, several factors may account for the discrepancy between our findings and those of Margulies and Hammer (1991), including the drug used (THC vs. WIN 55212-2), the doses (higher in the previous study), and the route of administration. With respect to this latter issue, there is evidence that the metabolic increase in the nucleus accumbens, and the shell subportion in particular, following the administration of several abused drugs is strictly dependent on the intravenous route of injection (Porrino 1993; Pontieri et al. 1998). Furthermore, the analysis of the shell and core subportions of the nucleus accumbens was not performed in the previous study. Finally, the study by Margulies and Hammer (1991) was not quantitative, so they would not necessarily detect the same changes as in the present study, due to any potential effect of the drug in the white matter.

As mentioned previously, the experimental definition of the addictive properties of cannabinoid agonists has been limited by difficulties in obtaining stable rates of self-administration by laboratory animals. However, self-administration of WIN 55212-2 in the mouse has been reported recently (Martellotta et al. 1998), using the intravenous drug injection of $0.1 \mathrm{mg} / \mathrm{kg}$. Conversely, higher doses of the drug produced aversion on the same behavioral paradigm. The results of the present study may be relevant to further clarify the ad- 
dictive potentials of cannabinoids since they show selective increase of glucose metabolism in the shell of the nucleus accumbens following the intravenous administration of $0.15 \mathrm{mg} / \mathrm{kg}$ of WIN 55212-2 in the rat. However, the observation that higher dose of WIN 55212-2, still able to increase extracellular dopamine in the shell (Tanda et al. 1997), does not modify energy metabolism in this area, whereas it reduces glucose utilization in the hippocampal formation, suggests that the functional activation of the accumbens shell by cannabinoids may be counteracted by the reduction of functional activity throughout the memory pathways.

\section{ACKNOWLEDGMENTS}

We thank M. La Riccia for the excellent technical assistance. This work was supported by grants from MURST $40 \%$ and $60 \%$ ("Neurobiologia delle tossicodipendenze e dei meccanismi di gratificazione naturale").

\section{REFERENCES}

Brodkin J, Moerschbaecher JM (1997): SR 141716A antagonizes the disruptive effects of cannabinoid ligands on learning in mice. J Pharmacol Exp Ther 282:1526-1532

Crane AM, Porrino LJ (1989): Adaptation of the quantitative $2-\left[{ }^{14} \mathrm{C}\right]$ deoxyglucose method for use in freely moving rats. Brain Res 499:87-92

Diana M, Melis M, Muntoni AL, Gessa GL (1997): Mesolimbic dopaminergic decline after cannabinoid withdrawal. Proc Natl Acad Sci USA 95:10269-10273

Gardner EL, Vorel SR (1998): Cannabinoid transmission and reward-related events. Neurobiol Dis 5:502-533

Gessa GL, Mascia MS, Casu MA, Carta G (1997): Inhibition of hippocampal acethylcholine release by cannabinoids: Reversal by SR 141716A. Eur J Pharmacol 327:R1-2

Gessa GL, Melis M, Muntoni AL, Diana M (1998): Cannabinoids activate mesolimbic dopamine neurons by action on cannabinoid CB1 receptors. Eur J Pharmacol 341:39-44

Lichtman AH, Martin BR (1996): Delta 9-tetrrahydrocannabinol impairs spatial memory through a cannabinoid receptor mechanisms. Psychopharmacology 126:125131

Mallet PE, Beninger RJ (1998): Delta 9-tetrahydrocannabinol, but not the endogenous cannabinoid receptor ligand anandamide, produces conditioned place avoidance. Life Sci 62:2431-2439
Mansbach RS, Rovetti CC, Winston EN, Lowe JA 3rd (1996): Effects of the cannabinoid CB1 receptor antagonist SR141716A on the behavior of pigeons and rats. Psychopharmacology 124:315-332

Margulies JE, Hammer RP Jr (1991). Delta 9-tetrahydrocannabinol alters cerebral metabolism in a biphasic, dosedependent manner in the rat brain. Eur J Pharmacol 202:373-378

Martellotta MC, Cossu G, Fattore L, Gessa GL, Fratta W (1998): Self-administration of the cannabinoid receptor agonist WIN 55212-2 in drug-naive mice. Neuroscience 85:327-330

Orzi F, Passarelli F, La Riccia M, Di Grezia R, Pontieri FE (1996): Intravenous morphine increases glucose utilization in the shell of the rat nucleus accumbens. Eur J Pharmacol 302:49-21

Pontieri FE, Colangelo V, La Riccia M, Pozzilla C, Passarelli F, Orzi F (1994): Psychostimulant drugs increase glucose utilization in the shell of the rat nucleus accumbens. NeuroReport 5:2561-2564

Pontieri FE, Tanda G, Di Chiara G (1995): Intravenous cocaine, morphine and amphetamine preferentially increase extracellular dopamine in the "shell" as compared to the "core" of the rat nucleus accumbens. Proc Natl Acad Sci USA 92:12304-12308

Pontieri FE, Tanda G, Orzi F, Di Chiara G (1996): Effects of nicotine on the nucleus accumbens and similarity to those of addictive drugs. Nature 382:255-257

Pontieri FE, Passarelli F, Calò L, Caronti B (1998): Functional correlates of nicotine administration: Similarity with drugs of abuse. J Mol Med (JMM) 76:193-201

Porrino LJ (1993): Functional consequences of cocaine administration depend on the route of administration. Psychopharmacology 112:343-351

Rodriguez de Fonseca F, Carrera MRA, Navarro M, Koob GF, Weiss F (1997): Activation of corticotropin-releasing factor in the limbic system during cannabinoid withdrawal. Science 276:2050-2054

Sakai ST, Grofova I, Bruce K (1998): Nigrothalamic projections and nigrothalamocortical pathways to the medial agranular cortex in the rat: Single- and double-labeling light and electron microscopic studies. J Comp Neurol 391:506-525

Sokoloff L, Reivich M, Kennedy C, DesRosiers MH, Patlak CS, Pettigrew KD, Sakurada O, Shinohara M (1977): The $\left[{ }^{14} \mathrm{C}\right]$ deoxyglucose method for the measurement of local cerebral glucose utilization: Theory, procedure and normal values in the conscious and anesthetized albino rat. J Neurochem 28:897-916

Tanda G, Pontieri FE, Di Chiara G (1997): Cannabinoid and heroin activation of mesolimbic dopamine transmission by a common $\mu 1$ opioid receptor mechanism. Science 276:2048-2050 